\title{
Disintermediating Government: The role of Open Data and Smart Infrastructure
}

\author{
Peter A Johnson, PhD \\ University of Waterloo \\ peter.johnson@uwaterloo.ca
}

\begin{abstract}
Governments are increasingly negotiating the adoption of civic technologies to improve government functioning and to better connect with citizens. Despite the benefits of civic technology to make government more efficient, effective, and transparent, there are many challenges and even unintended outcomes to civic technology adoption. This exploratory paper presents a conceptual argument using two types of civic technology; open data and smart city infrastructure, as examples where their procurement by government can disintermediate government from citizen. This disintermediation can have both positive and negative outcomes for different parties. Four mechanisms that drive this disintermediation are discussed, including the use of legal frameworks, jumping of scales, conversion of public to private goods, and the creation of standards. These mechanisms can serve to shift the role of government from a service provider to a more background role as a data custodian or regulator, opening many opportunities for other actors, including private sector to assume critical roles in service provision.
\end{abstract}

\section{Introduction}

Technology has long been used to improve the efficiency and effectiveness of government. Whether through the adoption of information management systems, geographic information systems (GIS), the provision of documents online through e-government initiatives, or by instrumenting a city with real-time sensors, technology plays a strong role in how governments provide services to citizens [24]. Recently, governments around the world are engaging with a class of technology defined by the umbrella term of "civic technology". Civic technology is any type of technology adopted by government for the purposes of supporting the relationship of government to citizen [16, 29]. This citizen-facing aspect differentiates civic technology from general technology procurement typically directed towards internal purposes. For example, a smartphone app to provide citizens with government information, real-time schedules, and a platform for providing feedback, is a common form of civic technology. Additional examples include the provision of municipal wireless internet connections [26], bulk open data provision [2], the instrumentation of cities with smart sensors [36], as well as government support of in-person events or incubators that encourage citizen use or reuse of government data [22].

This provision of civic technology is often supported by open government policies that aim to make government more transparent, accountable, and by association, seem more forward-thinking and 'innovative' [9, 37]. Despite the strong potential for civic technology to improve government-citizen interactions, and increase both the efficiency and impact of municipal actions, there are also notable challenges and a potential 'dark side' of unintended consequences to technology adoption and implementation [23, 42]. Given the wide variety of civic technology types, literature on this topic largely focuses on two types; open data [23, 42], and smart city infrastructure development $[27,36]$. This general framing places open data and smart city infrastructure as a public subsidy of the private sector and opening doors to the outsourcing of government services $[17,38]$. It is this latter point, the potential for open data and smart city infrastructure, to feed the disintermediation of government by private sector actors that is the focus of this exploratory paper.

The use of private sector companies for the procurement of government technology and development of citizen-facing services is not new, however in the context of civic technology, the impact of this transfer of development to a third party demands investigation $[8,16]$. As government rushes to thirdparties to procure civic technology, there is the potential that government itself is disintermediated [6,37]. Civic technology then becomes a vector through which alternate or parallel services are provided to citizens, by third-parties, with background support from 
government, via the adoption of civic technology. This process can have both positive and negative outcomes for different parties involved. For example, it is through this provision of open data by government that the private sector develops saleable products or services that replicate or parallel government products or services. This may benefit private sector companies, and potential end users through the creation of a service or produce that did not exist previously or was only marginally available. Alternately, this may simply weaken a government, further contributing to the neoliberalization of the state and outsourcing of public services to the lowest cost provider. This potential disintermediation of government through civic technology is the focus of this paper. Two main vectors for this disintermediation are explored, the first is through the provision of open data, and the second through the development of smart city infrastructure that is owned/operated by the private sector.

I take a critical view of the role of civic technology in mediating the complex relationship between government, citizens, and the private sector. There is current change in this relationship fueled through the differential adoption and application of civic technology across many government agencies throughout the world. There are many lessons to be learned and shared, and I aim to describe a potential near-future of how civic technology impacts government-citizen relationships. I use two examples, one data-focused, and one infrastructure-focused, to frame the potential of civic technology as a driver of the disintermediation of government and citizen. These examples are selected as they represent how technology is frequently applied in a city governance context - data to inform decisionmaking on public service and program provision, or as the infrastructure required to collect that data. First, the development and provision by government of open data, particularly the underlying motivations of enhancement of innovation and support of private-sector use of government data are examined for how this generates a shift from government as data creator, custodian, and user, towards a government as platform or government as data supplier paradigms. Second, the engagement of private development companies in the instrumentation of municipal landscapes (i.e., smart city developments) is used as an example of how civic technology focused on smart infrastructure deployment can result in the existence of parallel public/private infrastructure and data creation that places the third party between government and citizen.

\section{Citizen-Government Relationship}

Rapid change in the way that government, citizens, and the private sector relate to one another is being driven by civic technology [7, 22]. Many cities are experimenting with new ways of contracting services from the private sector, new ways of delivering and working with data, and even new ways of building physical and connected infrastructures $[31,33]$. In this context, I consider how government may become disintermediated from providing citizen-facing services, creating a system of parallel service provision, where government retreats from service provision completely $[21,23]$. Parallel service provision is when the private sector is providing services, typically directly to citizens that would traditionally be provided by government. This is framed as an intermediary step towards the more libertarian view of government as a platform [30], where government acts as a data or infrastructure provider, with third-parties intervening to provide or operate citizen-facing services. An infrastructure example of this government as platform would be where government invests to build a toll highway, but then turns over operation to a private company, who retains profits and carries the risk of operation. Similarly, a data-related example is when government provides open data on public parking availability, and the private sector develops a parking locator application. The recent increase in adoption of civic technology by municipal governments supports the realization of this government as a platform model, where government is reduced to acting not as the citizen-facing service provider, but as the data custodian [21, 32]. Government is disintermediated, that is separated from direct service provision, and relegated to a more supporting role, as the responsibility for service provision is passed to other actors. I frame this discussion using two examples where this disintermediation is realized; open data provision, and the development of smart city infrastructure.

\subsection{Open Data as a Platform for Disintermediation}

The delivery of open data is a focus of many open government programs around the world [13]. Governments provide access to government data, subject to a generous use license. Motivations for the delivery of open data often focus on the use of open data within an agenda of increasing government transparency and enabling private-sector innovation $[18,19]$. This innovation aspect implies that government lacks the expertise, mandate, or resources to fully exploit government data in service of citizens. As described in O'Reilly [30] this provision of data represents a government as platform concept, where external parties use government data or resources to create value, where the cost of providing access to data or a platform of services is exceeded in value generated 
by users of the platform [25]. For example, the value generated with the use of a computer operating system vastly exceeds the value of the operating system returned to the developer.

Through the provision of open data, government both supports this innovation agenda, and a data ecosystem that can generate benefits for the private sector and citizens [14, 40]. Open data provision also can support the disintermediation of government from direct service provision to citizens. For example, the provision of open data may force government to relinquish certain roles, retreating to the role of supplier to third parties, data creator/custodian, rather than service provider or data analyst [5]. This creates an opening for the private sector to duplicate or improve on government service provision [1, 37]. Though many of these private sector products created with open data may not be within the mandate of government, they still represent an opportunity for the private sector to intervene between citizen and government, using a technical backend created by government. This related impact of open data represents a mechanism of disintermediation of government and citizen.

\subsection{Creating a Private City with Smart City Infrastructure}

Disintermediation of government via civic technology also occurs through the development and operation of smart cities infrastructure [36]. Though cities have long contracted out infrastructure development, the 'smart' characteristics of a smart city change this process, with additional citizen interaction and data extraction layered on top of the actual infrastructure itself [4, 41]. For example, not only do private sector actors create the infrastructure, and operate it, but they also connect citizens using the infrastructure to existing public/private networks. This represents a physical manifestation of the retreat of government from the citizen-facing service delivery model, and towards the regulator or convener model typified through public-private partnership development [34]. As presented by Scassa [35], cities begin to relinquish ownership of data collection, becoming 'data tenants', rather than 'data landlords'. It is this transition from the complete ownership and stewardship over public infrastructure, towards playing a merely convening role that creates the potential for government to be disintermediated from the citizen, replaced instead by the private sector.

The recent development of smart cities is wellrepresented by the Google Sidewalk Labs development in Toronto, Canada [27]. This partnership between Sidewalk Labs and Waterfront Toronto, a public agency tasked with redeveloping a significant piece of prime waterfront real estate, aims to develop an instrumented, connected landscape where citizens, government, and the private sector interact through smart technology. The main goals of this project are improved sustainability, citizen convenience, and effectiveness of urban infrastructure [27]. Though currently evolving, this project represents the disintermediation of government from the land development and city building mandate, using the context of improved technological innovation as a driver. Though still implicated in a regulatory context, such as through traditional building permit and zoning regulation, the role of government and associated opportunities for legislated citizen input, is reduced, and redirected to a non-elected and less accountable private sector company. Throughout the Sidewalk Toronto process significant questions have been raised, often by parties external to the official process, as to how data ownership, protection of public good, and privacy of citizen data will be handled [39]. This provides an incisive example of the issues that governments are already facing and that many more will face in the near future, when procurement and implementation of smart cities infrastructure, driven by actors external to government, aim to disintermediate sections of the government-citizen relationship. These openings allow the private sector to assume the role of government, even in a small way, with no direct mechanism for government to re-insert itself.

\section{Mechanisms of Government Disintermediation}

I propose four mechanisms for how civic technologies, despite the many real intended benefits that they provide, may also produce unintended consequences that drive government-citizen disintermediation. This disintermediation process itself may have positive outcomes for different parties. Given this mixed potential for positive and negative outcomes, I present these mechanisms as broad considerations to municipal governments that are investing in civic technology, from the perspective of how government retains or relinquishes control over service provision. For municipal governments interested in procuring civic technology or developing related programs, these are areas that are of significant consideration. A civic technology can disintermediate government from citizen through the following four mechanisms:

\subsection{Use of legal or other frameworks to separate government from citizen}


One mechanism used by private sector companies to disintermediate government from citizen through the application of civic technology include the use of legal or quasi-legal frameworks, such as copyright, data ownership, and terms of service. This mechanism is used in the creation of a 'walled garden', where value added products created by the private sector are protected as copyrighted material or require users to abide by terms of service to access. For example, a private sector company accesses government open data to create a transit schedule or map routing application. This creates a copyrighted product (the app) that is protected by a terms of service agreement with the user. This agreement may require specific concessions on the part of the user/citizen in terms of data privacy, user location access, and create new restrictions on how the product, based at least in part on open government data, is accessed and used. This creation of a 'walled garden' to protect private sector interests effectively repackages government open data and places rules to govern access and use. Additional access steps such as a login, registration, or other access control mechanism also place additional layers of disintermediation between government and citizen, for example, by tying access to premium services created with government data to logins that use social media (such as Facebook) or authoritative identity providers (such as Google) to control login. This type of strategy places these private sector entities as the arbiters of access to value-added services that are more attractive, user-friendly, and importantly, connected to existing private sector services (such as social media) that many citizens already use.

This mechanism is also present in the instrumentation of urban spaces by private sector companies via smart city developments. This creates an opportunity for the private sector to use the mechanism of legal frameworks to disintermediate citizen and government. This mechanism can operate through the ownership of data streams created through smart city infrastructure, turning government into a downstream data user, with private sector taking on the role of data steward.

\subsection{Jumping Scales between jurisdictions and services}

The process of jumping scales, that is moving from an issue or concern operationalized at a local scale, to one at a regional, national, or international scale is considered to be jumping scales [15]. This mechanism allows for actors at certain scales to leverage actors located at alternate scales to effect change. Scale jumping presents a mechanism through which the private sector can use civic technology to disintermediate citizen and government. For example, the private sector, as an entity that can more easily operate across different government jurisdictions (throughout a state or country, for example), is strategically placed to play the role of an aggregator across different governments, pulling together similar services to create a seamless experience for citizens. This ability to see and act beyond traditional political borders provides an opportunity for the private sector to disintermediate government from citizen service provision. For example, aggregating government data on recreational bicycle trails could be used to create a product for citizens that crosses regional political borders and is thus more useful and attractive compared to jurisdictionally-bound services. Citizens begin to turn towards the private sector provider as the authoritative source of this information, due to its comprehensiveness. Through this process of scale jumping, government begins to lose control over data and process as the citizen facing product becomes less bound by local convention and citizen desires.

\subsection{Conversion of public good to private profit.}

A significant mechanism that supports the disintermediation of government and citizen is the transformation of data or infrastructure provided as a public good, towards one that is provided as a consumable product, generating profit for private enterprise. The use of this mechanism in the case of open data is longstanding, as a primary motivation for the release of open data is to support private sector innovation [12, 43]. Frequent exhortations refer to 'unlocking value', or 'increasing innovation', though the exact amount of value and its nature is often difficult to determine [11]. More likely, the generation of value and saleable products from open data draws citizen or user attention away from the raw provision of open data and towards the entity (frequently a private entity) that has created the interface for data use and application. This disintermediation is another example of where civic technology provides an opening for the private sector to assume the role of service provider to citizen, relegating government to a background data custodian. This type of disintermediation is also apparent in smart city infrastructure development projects, where the private sector deploys smart city technology as part of improving city neighbourhoods, realizing a real-estate upselling. The current Google Sidewalk project is showcased as this, taking vacant industrial land and converting it to prime real estate through the creation of a smart district [27]. This takes public land, which could be repurposed for any number of projects, and converts it through the application of private vision and infrastructure. 


\subsection{Creation of standards that build on existing areas of third-party strength}

An identified constraint to the private sector use of civic technology, such as open data, is the provision of data by government according to accepted standards. Standardization of data facilitates the reuse of data, and eases the development of applications that cross various jurisdictions. The development of standards, while having many benefits to support the use of open data, also facilitate a mechanism that supports private sector disintermediation of government from citizen [3]. For example, the development of the General Transit Feed Specification (GTFD) real-time transit data standard by Google directly supports the inclusion of real-time transit schedules within consumer-facing products, such as Google Maps [28]. This is a positive development for consumers, in that they have access to seamless transit schedules via one app. This type of application is only possible with the use of the same set of standards by many different government transit agencies. Before widespread adoption of the GTFS standard, each transit authority would be responsible for producing consumerfacing schedules, whether print or digital. With the standardization based around GTFS, this has opened a new world where citizens interact with government data, yet this is through the portal owned, operated, and for the benefit of Google. This creates a Google platform that is 'stickier', with a wide variety of features, keeping the user within their ecosystem, despite an underlying reliance on government to continue to provide transit data within a certain format. From an infrastructure perspective, this disintermediation continues, with technical standards for infrastructure and interoperability set by smart city vendors, ensuring that municipal procurement can be leveraged across different cities. For example, the use of proprietary technologies to connect infrastructure results in not only procurement benefits for specific companies, but also the entrenchment of specific technologies as the technology of choice. This allows private companies to play the role of service provider most directly, as government has neither the role nor technical resources to develop, install, or maintain advanced technology. This is particularly true when comparing smart infrastructure to traditional infrastructure, where city government takes responsibility for install and maintenance on a city asset.

\section{Civic Technology as a Vehicle for Government Disintermediation}

Civic technology has proven in many instances as a vehicle for improving government transparency [20], opening government data for use [10], and for improving how cities function [3]. However, civic technology also runs the risk of creating an environment and context that disintermediates government from citizen, with both positive and negative outcomes from this disintermediation. From a government perspective, a negative outcome from this disintermediation could be the neoliberal weakening of the government role within service and infrastructure provision, allowing the private sector to assume these roles to varying effect. As presented here, there are mechanisms through which civic technology enables this disintermediation, though this is not an exhaustive list. Despite the potential gains provided by civic technology, there are considerations that may be ignored as a result of this disintermediation, including traditional government concerns of equity, inclusivity, and strengthening of the greater public good - concerns that may not resonate as meaningfully for services and products provided by the private sector, based on openings provided by civic technology adoption. For example, government must focus on concerns of inclusion [23], providing for all citizens, in contrast to the private sector focus on paying customers and return to shareholders. For some applications of civic technology, a private sector focus may generate real benefits for users and for government, however this is not universal for all government services and programs where civic technology may be applied. This role of government as the steward of the public good means that the government horizon must extend far into the future, guarding against risk to the state and population. Again, this contrasts to a private sector timeline that is shorter and profit-focused [5]. Ultimately, in the provision of services to citizens, through the adoption of civic technology, including open data and smart city infrastructure, government relinquishes authority and accountability to the private sector. This matches the general shift of neoliberalism, where the private sector assumes the role of government, disintermediating it from the citizen.

The role of civic technology in this disintermediation is significant. As civic technologies such as open data and smart city infrastructure are adopted, the role of the private sector in implementing and realizing the benefits of these technologies grows. This pushes government to become a supplier or broker of data and infrastructure access, rather than as a developer or user. Government data and city infrastructures become commodities, freeing private companies to act as aggregators, extracting the value from government as a platform. Perhaps we have seen the government as platform vision come into reality, with far greater value created external to the functions 
of government itself. The challenge here is defining value for whom. This is particularly relevant as government is in charge of the public good, raising questions if government can continue to justify building out civic technology as a vector for private sector value, even as government loses influence on that process by relinquishing data gathering, use, and service roles. The four mechanisms presented here sketch out an early vision of how government is being disintermediated from the citizen through the adoption of civic technology. The disintermediation of government is not a given, and the future of government and the breadth and depth of its role in daily life is constantly unfolding. For those governments procuring civic technology, let these unknown impacts and effects serve as important considerations in the process of technology procurement, adoption, and implementation.

\section{References}

[1] Ahmadi Zeleti, F., A. Ojo, and E. Curry, "Exploring the economic value of open government data", Government Information Quarterly 33(3), 2016, pp. 535-551.

[2] Attard, J., F. Orlandi, S. Scerri, and S. Auer, "A systematic review of open government data initiatives", Government Information Quarterly 32(4), 2015, pp. 399-418.

[3] Attard, J., F. Orlandi, S. Scerri, and S. Auer, "A systematic review of open government data initiatives", Government Information Quarterly 32(4), 2015, pp. 399-418.

[4] Bartenberger, M., and V. Grubmüller, "The Enabling Effects of Open Government Data on Collaborative Governance in Smart City Contexts", eJournal of eDemocracy \& Open Government 6(1), 2014, pp. 36-48.

[5] Bates, J., "The politics of open government data: a neo-gramscian analysis of the United Kingdom's Open Government Data initiative", 2012. http://espace.openrepository.com/e-space/handle/2173/303783

[6] Bates, J., “"This is what modern deregulation looks like' : co-optation and contestation in the shaping of the UK's Open Government Data Initiative", The Journal of Community Informatics 8(2), 2012.

[7] Bates, J., "The Domestication of Open Government Data Advocacy in the United Kingdom: A Neo-
Gramscian Analysis", Policy and Internet 5(1), 2013, pp. 118-137.

[8] Batty, M., "Dissecting the streams of planning history: technology versus policy through models", Environment and Planning B: Planning and Design 31(3), 2004, pp. 326-330.

[9] Bedini, I., F. Farazi, J. Pane, I. Tankoyeu, D. Leoni, and S. Leucci, "Open government data: Fostering innovation", eJournal of eDemocracy \& Open Government 6(1), 2014.

[10] Bertot, J.C., P.T. Jaeger, and J.M. Grimes, "Using ICTs to create a culture of transparency: E-government and social media as openness and anti-corruption tools for societies", Government Information Quarterly 27(3), 2010, pp. 264-271.

[11] Bonina, C.M., "New business models and the value of open data: definitions, challenges and opportunities", (August), 2013.

[12] Chan, C.M.L., "From Open Data to Open Innovation Strategies: Creating E-Services Using Open Government Data", IEEE (2013), 1890-1899.

[13] Charalabidis, Y., C. Alexopoulos, and E. Loukis, "A Taxonomy of Open Government Data Research Areas and Topics", Journal of Organizational Computing and Electronic Commerce, 2016.

[14] Charalabidis, Y., E. Loukis, and C. Alexopoulos, "Evaluating Second Generation Open Government Data Infrastructures Using Value Models”, 2014 47th Hawaii International Conference on System Sciences, 2014, pp. 2114-2126.

[15] Cox, K., "Spaces of dependence, spaces of engagement and the politics of scale, ore looking for local politics", Political Geography 17(1), 1998, pp. 123.

[16] Desouza, K.C., and A. Bhagwatwar, "Technology-Enabled Participatory Platforms for Civic Engagement: The Case of U.S. Cities", Journal of Urban Technology 21(4), 2014, pp. 25-50.

[17] Gurstein, M.B., "Open data: Empowering the empowered or effective data use for everyone?", First Monday 16(2), 2011.

[18] Huijboom, N., and T. Van den Broek, "Open data: an international comparison of strategies", European journal of ePractice 12(1), 2011, pp. 4-16. 
[19] Janssen, M., Y. Charalabidis, and A. Zuiderwijk, "Benefits, Adoption Barriers and Myths of Open Data and Open Government", Information Systems Management 29(4), 2012, pp. 258-268.

[20] Janssen, M., and J. van den Hoven, "Big and Open Linked Data (BOLD) in government: A challenge to transparency and privacy?", Government Information Quarterly 32(4), 2015, pp. 363-368.

[21] Johnson, P.A., "Models of direct editing of government spatial data: challenges and constraints to the acceptance of contributed data", Cartography and Geographic Information Science 44(2), 2017, pp. 128138.

[22] Johnson, P.A., and P. Robinson, "Civic Hackathons: Innovation, Procurement, or Civic Engagement?: Civic Hackathon: Procurement or Civic Engagement?", Review of Policy Research 31(4), 2014, pp. 349-357.

[23] Johnson, P.A., R. Sieber, T. Scassa, M. Stephens, and P. Robinson, "The Cost(s) of Geospatial Open Data.", Transactions in GIS 21(3), 2017, pp. 434-445.

[24] Jun, K.N., and C. Weare, "Institutional Motivations in the Adoption of Innovations: The Case of E-Government", Journal of Public Administration Research and Theory 21(3), 2011, pp. 495-519.

[25] Kenney, M., and J. Zysman, "The Rise of the Platform Economy", Issues in Science and Technology 32(3), 2016, pp. 61-69.

[26] Lehr, W., M. Sirbu, and S. Gillett, "Wireless is changing the policy calculus for municipal broadband", Government Information Quarterly 23(3-4), 2006, pp. 435-453.

[27] Lorinc, J., Promise and Peril in the Smart City: Local Government in the Age of Digital Urbanism, University of Toronto Institute on Municipal Finance and Governance, 2018.

[28] McHugh, B., "Pioneering Open Data Standards: The GTFS Story", In B. Goldstein and L. Dyson, eds., Beyond transparency: open data and the future of civic innovation. 2013, 125-135.

[29] Nath, J., "Reimagining government in the digital age", National Civic Review 100(3), 2011, pp. 19-23.

[30] O’Reilly, T., "Government as a Platform", innovations 6(1), 2011, pp. 13-40.
[31] Paroutis, S., M. Bennett, and L. Heracleous, “A strategic view on smart city technology: The case of IBM Smarter Cities during a recession", Technological Forecasting and Social Change 89, 2014, pp. 262-272.

[32] Ranerup, A., H.Z. Henriksen, and J. Hedman, “An analysis of business models in Public Service Platforms", Government Information Quarterly 33(1), 2016, pp. 6-14.

[33] Roche, S., "Geographic information science III: Spatial thinking, interfaces and algorithmic urban places-Toward smart cities", Progress in Human Geography, 2016.

[34] Rocheleau, B., and L. Wu, "Public versus private information systems: Do they differ in important ways? A review and empirical test", American Review of Public Administration 32(4), 2002, pp. 379-397.

[35] Scassa, T., "Sharing Data in the Platform Economy: A Public Interest Argument for Access to Platform Data”, UBC Law Review 50(4), 2017.

[36] Shelton, T., M. Zook, and A. Wiig, "The 'actually existing smart city", Cambridge Journal of Regions, Economy and Society 8(1), 2015, pp. 13-25.

[37] Sieber, R.E., and P.A. Johnson, "Civic open data at a crossroads: Dominant models and current challenges", Government Information Quarterly 32(3), 2015, pp. 308-315.

[38] Viitanen, J., and R. Kingston, "Smart Cities and Green Growth: Outsourcing Democratic and Environmental Resilience to the Global Technology Sector", Environment and Planning A 46(4), 2014, pp. 803-819.

[39] Wylie, B., "Sidewalk Toronto - The Plan for R\&D with Our Civic Data Finally Comes Into Focus", Bianca Wylie, 2018. https://biancawylie.com/?p=123

[40] Yang, T.-M., J. Lo, H.-J. Wang, and J. Shiang, "Open Data Development and Value-added Government Information: Case Studies of Taiwan eGovernment", Proceedings of the 7th International Conference on Theory and Practice of Electronic Governance, ACM (2013), 238-241.

[41] Zook, M., "Crowd-sourcing the smart city: Using big geosocial media metrics in urban governance", Big Data \& Society 4(1), 2017, pp. 205395171769438. 
[42] Zuiderwijk, A., and M. Janssen, "The negative effects of open government data - investigating the dark side of open data", ACM Press (2014), 147-152.
[43] Zuiderwijk, A., M. Janssen, and C. Davis, "Innovation with open data: Essential elements of open data ecosystems", Information Polity 19(1, 2), 2014, pp. 17-33. 